\title{
Impact of the Three Gorges Dam, the South-North Water Transfer Project and water abstractions on the duration and intensity of salt intrusions in the Yangtze River estuary
}

\author{
M. Webber ${ }^{1}$, M. T. Li ${ }^{2}$, J. Chen ${ }^{2}$, B. Finlayson ${ }^{1}$, D. Chen ${ }^{3}$, Z. Y. Chen ${ }^{2}$, M. Wang ${ }^{1}$, and J. Barnett ${ }^{1}$ \\ ${ }^{1}$ School of Geography, The University of Melbourne, Parkville, Victoria 3010, Australia \\ ${ }^{2}$ State Key Laboratory for Estuarine and Coastal Research, East China Normal University, Shanghai 200062, China \\ ${ }^{3}$ College of Water Conservancy and Hydropower Engineering, Hohai University, Nanjing 210098, China
}

Correspondence to: M. Webber (mjwebber@unimelb.edu.au)

Received: 19 March 2015 - Published in Hydrol. Earth Syst. Sci. Discuss.: 13 May 2015

Revised: 27 August 2015 - Accepted: 5 October 2015 - Published: 2 November 2015

\begin{abstract}
This paper assesses the impacts of the Three Gorges Dam, the South-North Water Transfer Project and other water abstractions on the probability of long-duration salt intrusions into the Yangtze River estuary. Studies of intrusions of saltwater into estuaries are typically constrained by both the short duration of discharge records and the paucity of observations of discharge and salinity. Thus, studies of intrusions of saltwater into estuaries typically seek to identify the conditions under which these intrusions occur, using detailed observations for periods of 20-60 days. The paper therefore first demonstrates a method by which to identify the conditions under which intense intrusions of longduration occur and then applies that method to analyse the effect of the three projects. The paper constructs a model of the relationship between salinity and discharge and then employs Monte Carlo simulation methods to reconstruct the probability of observing intrusions of differing intensities and durations in relation to discharge. The model predicts that the duration of intrusions with chlorinity $\geq 250 \mathrm{mg} \mathrm{L}^{-1}$ (or $\geq 400$ or $500 \mathrm{mg} \mathrm{L}^{-1}$ ) increases as the number of consecutive days with discharge $\leq 12000 \mathrm{~m}^{3} \mathrm{~s}^{-1}$ (or $\leq 8000 \mathrm{~m}^{3} \mathrm{~s}^{-1}$ ) increases. The model predicts that in 1950-2014, the number of consecutive days with chlorinity $\geq 250 \mathrm{mg} \mathrm{L}^{-1}$ averaged $21.34 \mathrm{yr}^{-1}$; if the three projects operate according to their normal rules, that average would rise to $41.20 \mathrm{yr}^{-1}$. For a randomly selected year of discharge history from the period 1950-2014, under normal operating rules for these projects the probability of an intrusion rises from 0.25 (for 30-day
\end{abstract}

intrusions) or 0.05 (for 60 -day intrusions) to 0.57 or 0.28 , respectively.

\section{Introduction}

Shanghai's industries and the more than 24 million people who live in the municipality now principally depend on the Yangtze River for their water supply. Yet, like other large estuaries (Gong, 2013), the estuary of the Yangtze River is affected by salt intrusions (Shen et al., 2003). The latest occurred in 2014 (CNTV, 2014), the longest since 1993. So two storages have been built in the estuary to store water against the threat of salt intrusions (see Fig. 1 for locations): the Chenhang Reservoir supplies about $23 \%$ of the municipality's public water, and the Qingcaosha Reservoir supplies about $54 \%$ ( $\mathrm{Li}$ et al., 2014). Qingcaosha's storage capacity is said to be equivalent to 67 days of Shanghai's current consumption. The probability of long-duration salt intrusions in the Yangtze Estuary is thus of considerable social importance.

However, the discharge and tidal characteristics of the Yangtze Estuary are now being modified. Water is increasingly being abstracted from the river, for the South-North Water Transfer Project (SNWTP) as well as for more local uses (Chen, 2013; Zhang et al., 2012), tending to increase the length and the intensity of periods of low discharge (Li et al., 2014). The Yangtze River is increasingly being dammed for large hydroelectric projects that cumulatively can now store 


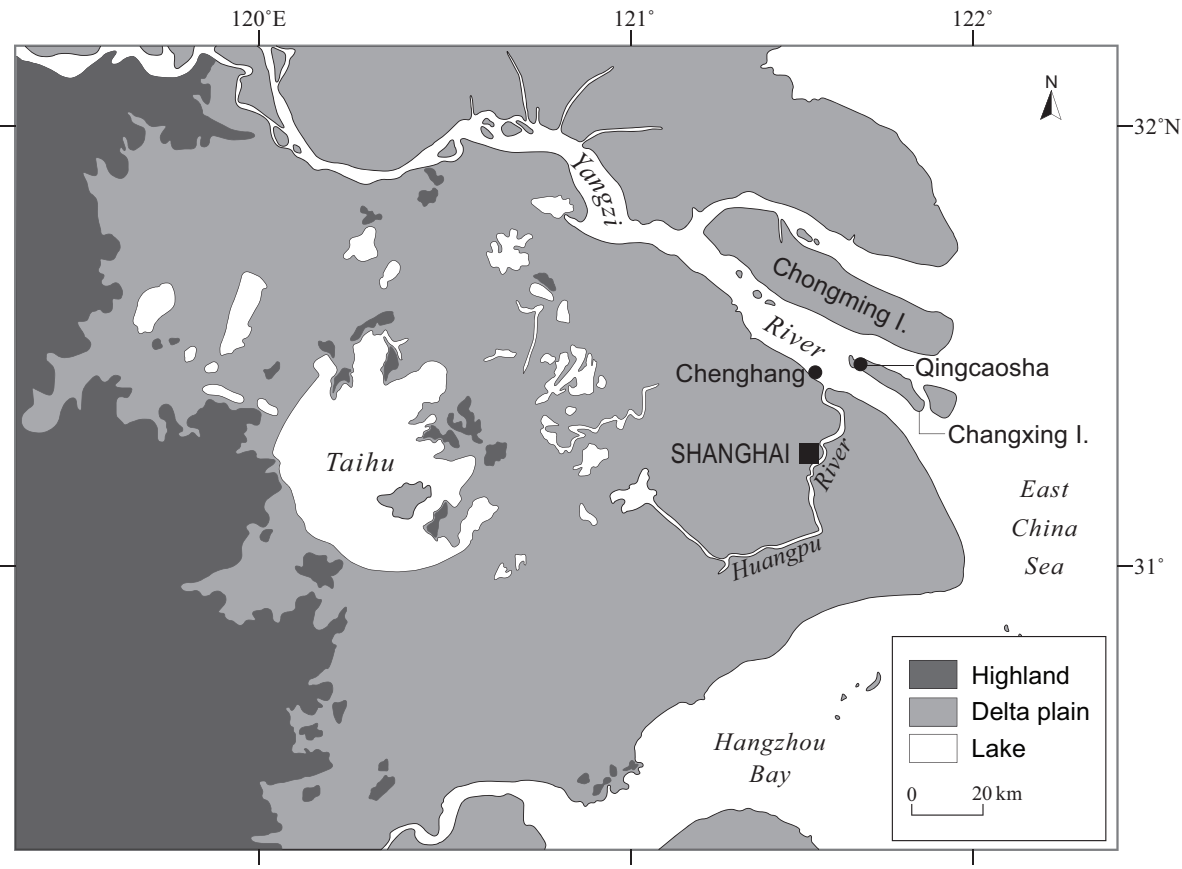

Figure 1. Map of Yangtze Estuary.

about $25 \%$ of the annual flow; this capacity is planned to double by 2050 ( $\mathrm{Li}$ et al., 2000). The largest of these hydroelectric dams is the Three Gorges Dam. As hydroelectric dams, these constructions have limited effects on annual discharge but do affect its seasonal distribution (Finlayson et al., 2013). All of these modifications will affect the probability of salt intrusions in the estuary and it is important to calculate their effects.

Intrusions of salt in estuaries have been widely studied, by both numerical and theoretical methods. Most studies of the Yangtze Estuary have been numerical (Kuang et al., 2009; Li et al., 2012; Liu et al., 2013; Xue et al., 2009). However, Zhang et al. (2011) applied Savenije's (1986, 1993) theoretical model. As Fig. 1 indicates, the Yangtze Estuary is complex, with four outlets to the sea. Nevertheless, these studies confirm that saltwater intrusions are primarily governed by a combination of low discharge and spring tide conditions but also influenced by wind speed and wind direction. The discharge of the Yangtze River is highly seasonal, with average discharges below $12000 \mathrm{~m}^{3} \mathrm{~s}^{-1}$ in January and February, compared to over $40000 \mathrm{~m}^{3} \mathrm{~s}^{-1}$ in JuneAugust (Chen, 2013; Finlayson, 2013). In dry years, discharges in December-March are below $12500 \mathrm{~m}^{3} \mathrm{~s}^{-1}$ (Wang et al., 2008). It is this period, December-March, in which intrusions are most likely to occur. When spring tides occur in December-March, intrusions are common: the lower the discharge and the higher the tide, the more intense the intrusion, especially when accompanied by strong south-easterly winds.
The principal problem for these studies has been to examine the conditions under which oceanic water intrudes far up the estuary. They seek to predict an event - the observation of water with chlorinity exceeding $250 \mathrm{mg} \mathrm{L}^{-1}$ (ppm, equivalent to 0.45 on the practical salinity scale), which is the Chinese standard for drinking water (National Standard GB 5749-2006). Since the usual treatment technologies in Shanghai's water plants do not remove chlorides, it is also the standard for raw water that is to be processed into tap water (Surface Water Quality Standards GB 3838-2002).

However, the duration of this event is also significant, especially for residents of Shanghai. An intrusion of a few days, no matter how intense, has little social significance, compared to an intrusion of a few months. Chen et al. (2013) do address duration, but they, like others (Chen et al., 2001; Gu and Yue, 2004; Wang et al., 2008; Yang, 2001; Zhao et al., 2009), identify a single threshold discharge below which intrusion is likely and above which intrusion is unlikely. In fact, salt intrusions may occur at a variety of discharges (Fig. 2), with a probability that varies inversely with discharge.

The difficulty is that, while long discharge records for many rivers are generally available, measurements of salinity are not routinely collected by state agencies. Salinity thus needs to be measured for a specific purpose, such as a research project. Measurements of salinity are therefore expensive and not available in long records. It is thus important to find a method for using historical data about discharge to generalise the limited observations of salinity and so obtain a long record of salinity, which identifies both the duration of a saline intrusion and the relative frequency of occurrence 

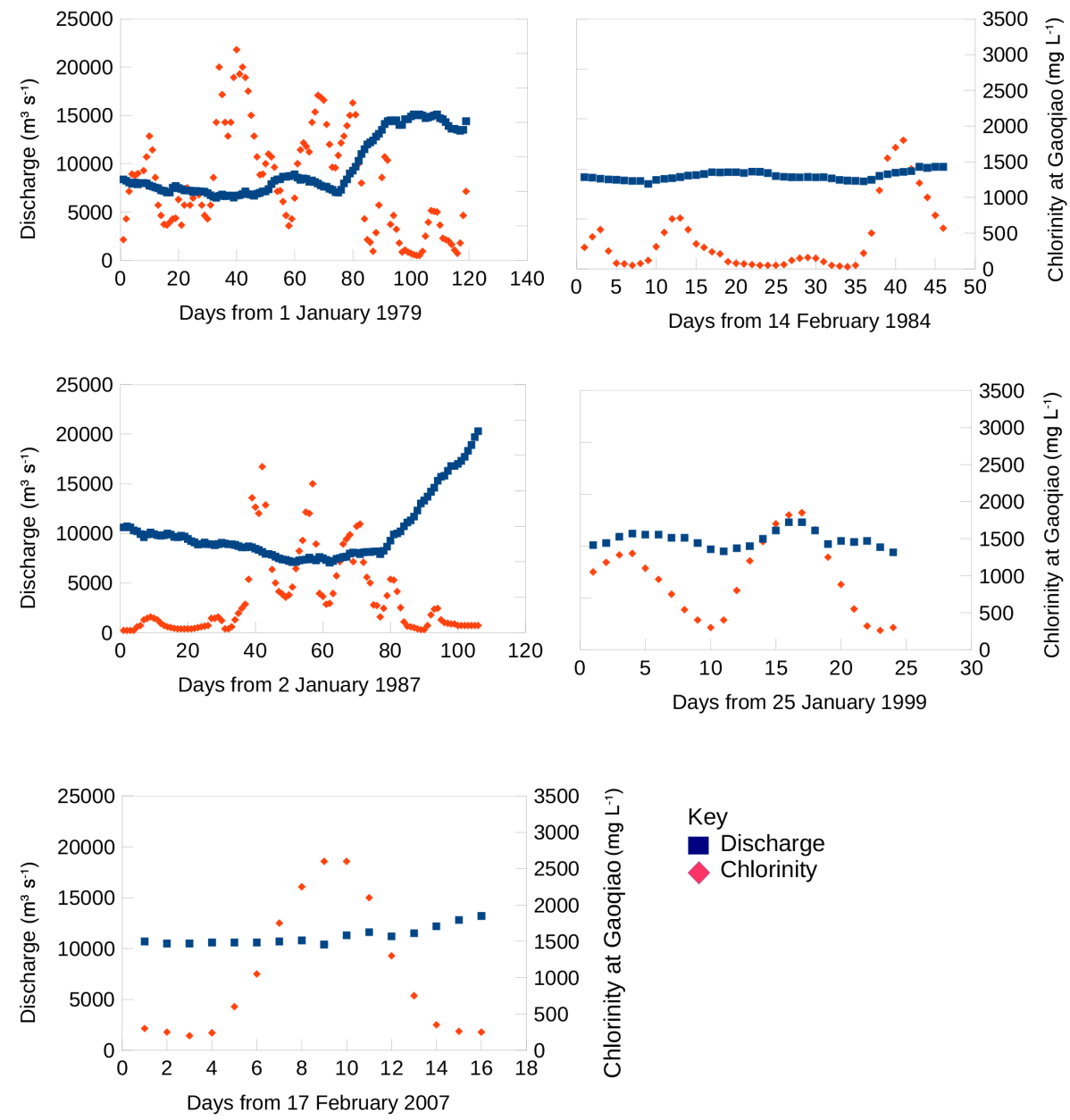

Figure 2. Chlorinity and discharge conditions in the periods of observation.

of such intrusions. It is this method that this paper presents and then employs to calculate both the probability of longduration salt intrusions in the Yangtze River estuary and the impact of human modifications of the river on that probability.

Specifically, the paper therefore addresses the following problems: how can the probability of long-duration (up to 60 days) salt intrusions in the Yangtze Estuary be identified? What is that probability? What is the effect on that probability of increasing water abstraction from the Yangtze Basin, the SNWTP and the construction of the Three Gorges Dam? It is our calculation of the probability of long-duration salt intrusions and our prediction of the impact on that probability of human modifications to discharge that sets this paper apart from other studies of salt intrusions in the Yangtze Estuary.

\section{Method}

This paper is statistical and predictive. We do not model the estuary dynamics, either theoretically or numerically, but es- timate statistical relations between discharge and salinity to identify the probability of long-duration salt intrusions. The paper draws on three sources of data.

First, it employs published data about discharge and salinity for various periods to estimate the relationship between discharge and salinity. The salinity data refer to the Gaoqiao gauging station in the estuary (Fig. 1), the nearest station to Qingcaosha, and are from Li et al. (2014). The discharges are measured at Datong, the nearest gauging station which has a long record of discharge data. The observations refer to the periods 1 January-30 April 1979 (120 observations), 13 February 1984-30 March 1987 (47 observations), 1 January-17 April 1987 (107 observations), 24 January17 February 1999 (25 observations) and 16 February4 March 2007 (17 observations). All 316 observations lie in periods in which the probability of low discharges and therefore of salt intrusions is high. Figure 2 illustrates the discharge and salinity conditions in these periods.

These observations are neither logically nor statistically independent. They are not taken on a random sample of days between 1 January 1979 and 4 March 2007, so they are not 
logically independent. A casual observation of Fig. 2, confirmed by statistical tests, reveals that there is a pronounced lag structure to the salinity measures, so they are not statistically independent either. An appropriate estimate of the relationship between discharge and salinity must recognise this non-independence of the observations. Although an artificial neural network could be constructed to model this relationship, we chose to estimate an equation of the form

$G_{t}=$ function $\left[G_{t-1}, Q_{t-7}\right]$,

in which $\mathrm{G}_{t}$, and $\mathrm{G}_{t-1}$ denote the salinity measure at Gaoqiao on day $t$ and $t-1$, respectively. $Q_{t-7}$ denotes the discharge at Datong on day $t-7$. At average discharges, it takes 7 days for water to flow from Datong to Gaoqiao (Zhang et al., 2012); the travel time is likely to be less at high discharges, though the fact that the average change in discharge from one day to the next is only $0.0094 \%$ renders this point moot.

Such a model has a straightforward, intuitive meaning. Observations are numbered $1,2, \ldots, n$ within years, and the estimates are made through a generalised estimating equation (Garson, 2013). After testing a variety of functional forms for Eq. (1) and assumptions about the distribution of residuals, the specific estimated equation is

$$
\begin{aligned}
\log G_{t}= & \alpha_{0}+\alpha_{1} \log G_{t-1}+\alpha_{2}\left(\log G_{t-1}\right)^{2}+\alpha_{3} Q_{t-7} \\
& +\alpha_{4} \log Q_{t-7}+\alpha_{5}\left(Q_{t-7}-Q_{t-8}\right)+r_{t}
\end{aligned}
$$

in which the residuals, $r_{t}$, are assumed to follow an inverse Gaussian distribution with autocorrelated variance structure, and $\alpha_{0}, \ldots, \alpha_{5}$ are parameters to be estimated. There are 312 usable observations, since the first day of each sequence is lost through the lag specification.

There are four known sources of error in the data that have been used to construct this equation. First, unknown, but variable, amounts of water are extracted from the river or drain into the river between Datong and the salinity gauging station at Gaoqiao. Zhang et al. (2012) estimate that net abstractions are highest in periods of spring tide, in September, October and November, and in years of drought (see also Dai et al., 2011). These differences are systematic though with imperfectly understood characteristics, which create errors of estimation. Secondly, the influence of spring and neap tides is not included (Tong et al., 2010, illustrate these effects). However, the partial autocorrelation plots of the residuals from Eq. (2) do not reveal any significant autocorrelations beyond day 1 . Third, there has been a rise in the long-term level of the sea. Cai et al. (2009) estimate that the rate of relative sea level rise in the Yangtze Delta has been accelerating and in the past few decades was $6.6 \mathrm{~mm} \mathrm{yr}^{-1}$. Over the period 1950-2010, this implies a rise of up to $40 \mathrm{~cm}$, which may influence the probability of an intrusion at any given discharge. Fourth are the errors of measurement within and differences in methods between the data sources, which are not known.

The second data set consists of the record of daily discharges at Datong. These are available for the period 19502007 from the published yearbooks of the Changjiang Water
Commission, with gaps that were kindly infilled by Klaus Fraedrich, and from 2004 to 30 September 2014 at the website of the Changjiang Shuiwei Guangli Xitong (Changjiang Water Level Management System; http://yu-zhu.vicp.net/). The record is converted from calendar years into "river years", which run from 1 August for 305 days; in a normal year, the sequence ends on 1 June and in a leap year on 31 May. Intrusions have never been observed in June and July. Once the parameters of Eq. (2) were estimated, those parameters and the distribution of residuals were used to create 1024 simulations of the corresponding salinities for each year $t$, using random numbers generated from the inverse Gaussian distribution of the estimated residuals, $r_{t}$. Thus, from the simulations we can then calculate for a year, with the discharge characteristics of year $t$, the probability of observing $1,2, \ldots, n$ consecutive days with salinity above the critical values of 250 (the upper limit of drinking water, according to the standard), 400 and $500 \mathrm{mg} \mathrm{L}^{-1}$ (values chosen to reflect the possibility of building water plants in Shanghai that can treat saline water to obtain drinking water). Repeating this calculation for each year provides the critical information which this paper seeks to present. The analysis concludes by illustrating the discharge characteristics of years in which the simulations reveal that the probability of longduration intrusions is high.

Thirdly, the paper relies on published information about the volumes and operating rules of local abstractions, the SNWTP and the Three Gorges Dam. In each case, we investigate the effect of two scenarios: the first, "normal operating rules" which represent our best estimate of abstractions out of the basin and discharges from the Three Gorges Dam; the second, "conservative operating rules" which assume that abstractions and changes in discharge are less severe than under normal operating rules. In both cases, it is assumed that current plans for the years 2030-2035 are followed. The details of these rules and the sources from which they were calculated are described in Appendix A; their effect on discharge into the estuary, net of return flows, is illustrated in Fig. 3. The impact of these modifications on the probability of long-duration intrusions is then calculated as follows: first, for the 64 river years from 1950-1951 to 2013-2014, what is the probability of an intrusion of given duration and chlorinity? Second, if the Three Gorges Dam, SNWTP and local abstractions planned for 2030-2035 had operated from 1950-1951 to 2013-2014, what would have been the probability of an intrusion of given duration and chlorinity? The difference in probabilities is ascribed to the three modifications to the river.

The principal limitation of this analysis is the short duration of the time series of daily flows. There are only 64 river years of data from 1 January 1950 to 30 September 2014. Long periods of saline intrusion are relatively rare events, perhaps occurring no more than five times per century, so this record is clearly an insufficient basis from which to draw 
Table 1. Parameter estimates and goodness of fit.

\begin{tabular}{|c|c|c|c|c|c|c|c|}
\hline \multirow[t]{2}{*}{ Parameter } & \multirow[t]{2}{*}{$B$} & \multirow[t]{2}{*}{ SE } & \multicolumn{2}{|c|}{$95 \%$ Wald confidence interval } & \multirow{2}{*}{$\begin{array}{l}\text { Hypothesis test } \\
\text { Wald chi-square }\end{array}$} & \multirow[t]{2}{*}{ df } & \multirow[t]{2}{*}{ Significance } \\
\hline & & & Lower & Upper & & & \\
\hline Intercept & 4.923 & 1.761 & 1.471 & 8.374 & 7.814 & 1 & 0.005 \\
\hline Year $=1979$ & -0.015 & 0.0148 & -0.044 & 0.014 & 0.972 & 1 & 0.324 \\
\hline Year $=1984$ & -0.067 & 0.0069 & -0.080 & -0.054 & 95.507 & 1 & $<0.001$ \\
\hline Year $=1987$ & -0.085 & 0.0087 & -0.102 & -0.068 & 95.230 & 1 & $<0.001$ \\
\hline Year $=1999$ & 0.010 & 0.0032 & 0.004 & 0.016 & 10.084 & 1 & 0.001 \\
\hline Year $=2007$ & $0^{*}$ & & & & & & \\
\hline$Q_{\mathrm{d}}$ & $3.20 \times 10^{-5}$ & $1.59 \times 10^{-5}$ & $8.04 \times 10^{-7}$ & $6.32 \times 10^{-5}$ & 4.042 & 1 & 0.044 \\
\hline $\log Q_{\mathrm{d}}$ & -0.483 & 0.208 & -0.890 & -0.076 & 5.405 & 1 & 0.020 \\
\hline$Q_{\mathrm{d}}$ Diff & $2.95 \times 10^{-5}$ & $1.15 \times 10^{-5}$ & $6.94 \times 10^{-6}$ & $5.21 \times 10^{-5}$ & 6.562 & 1 & 0.010 \\
\hline $\log G_{\text {lag }}$ & 0.220 & 0.0185 & 0.184 & 0.256 & 141.042 & 1 & $<0.001$ \\
\hline $\log G_{\operatorname{lag}}^{2}$ & -0.008 & 0.002 & -0.012 & -0.004 & 17.497 & 1 & $<0.001$ \\
\hline Scale & 0.001 & & & & & & \\
\hline
\end{tabular}

SE: Standard error; df: degrees of freedom; ${ }^{*}$ set to zero, as parameter is redundant. Corrected quasi-likelihood goodness of fit: 20.341.
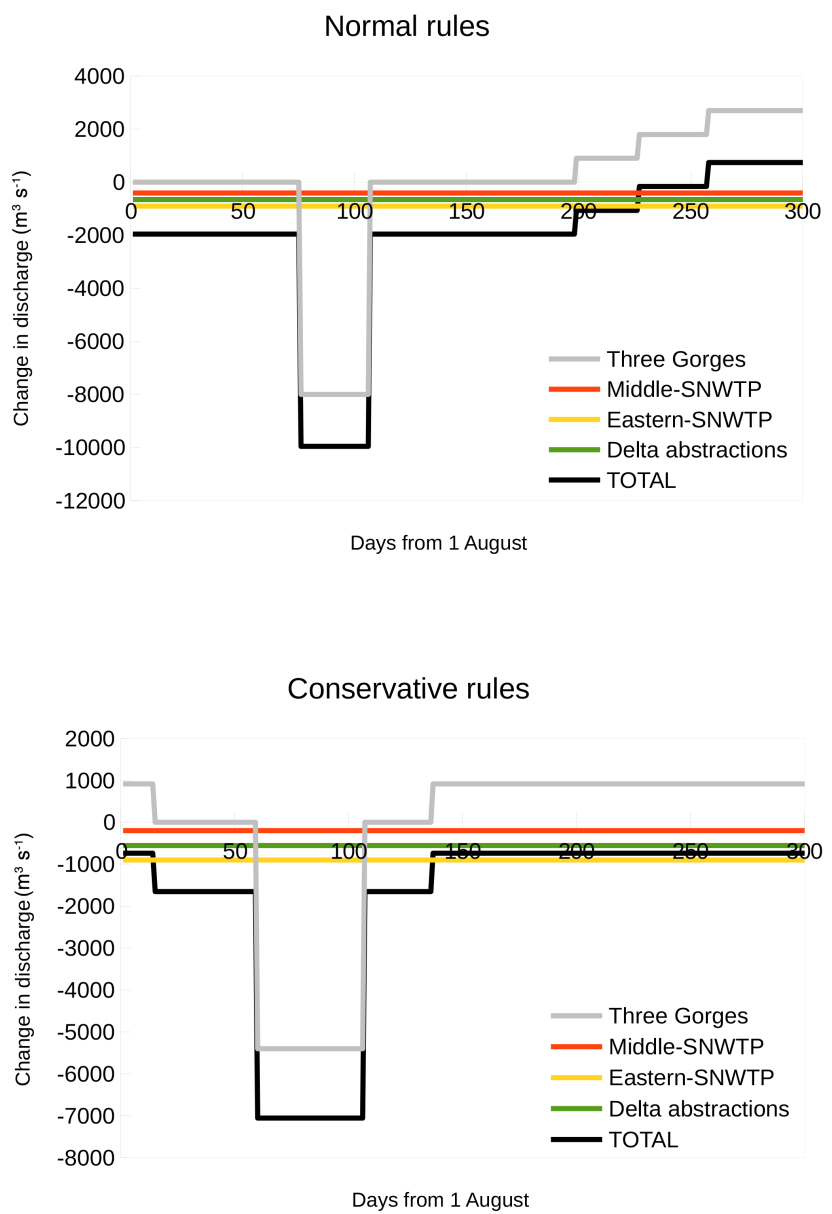

Figure 3. Change in discharge caused by normal and conservative operating rules for Three Gorges Dam, the South-North Water Transfer Project and local abstractions. robust conclusions about the relationship between low frequency, long-duration intrusions and river discharge.

\section{Results}

\subsection{Discharge and salinity}

The model estimates and goodness of fit criteria are contained in Table 1. The effect of all variables is significant at $p<0.05$, and the likelihoods are appropriately low. At the ranges of discharges to which the model was fit $(6000 \leq$ discharge $<16000)$ salinity is negatively associated with discharge and positively associated with the previous day's salinity. The proportion of the variance in $\log G$ that is accounted for by the model is 0.8893 . Residuals are not significantly different from normal, according to a one-sample Kolmogorov-Smirnov test; furthermore, the residuals are not correlated with the predicted values and their variance is approximately constant (Fig. 4).

The model predicts a close relation between discharge and mean salinity, especially when discharge falls for long periods below about $10000 \mathrm{~m}^{3} \mathrm{~s}^{-1}$. In 43 of the 64 years, the model predicts that there were periods in which mean salinity exceeded $250 \mathrm{mg} \mathrm{L}^{-1}$, ranging in length from 1 to 97 days; in 30 years there were periods in which mean salinity is predicted to have exceeded $400 \mathrm{mg} \mathrm{L}^{-1}$, ranging in length from 1 to 80 days; and in 25 years there were periods in which mean salinity is predicted to have exceeded $500 \mathrm{mg} \mathrm{L}^{-1}$, ranging in length from 1 to 70 days (Fig. 5). The model predicts that in 10 years $-1955,1956,1958,1962,1966$, 1967, 1971, 1978, 1979 and 1986, mean salinities of over $500 \mathrm{mg} \mathrm{L}^{-1}$ lasted more than 30 days. The model suggests that the Yangtze has become less liable to long-duration intense intrusions since 1986: no mean salinity of more than $500 \mathrm{mg} \mathrm{L}^{-1}$ is predicted to have exceeded 10 days since then. 

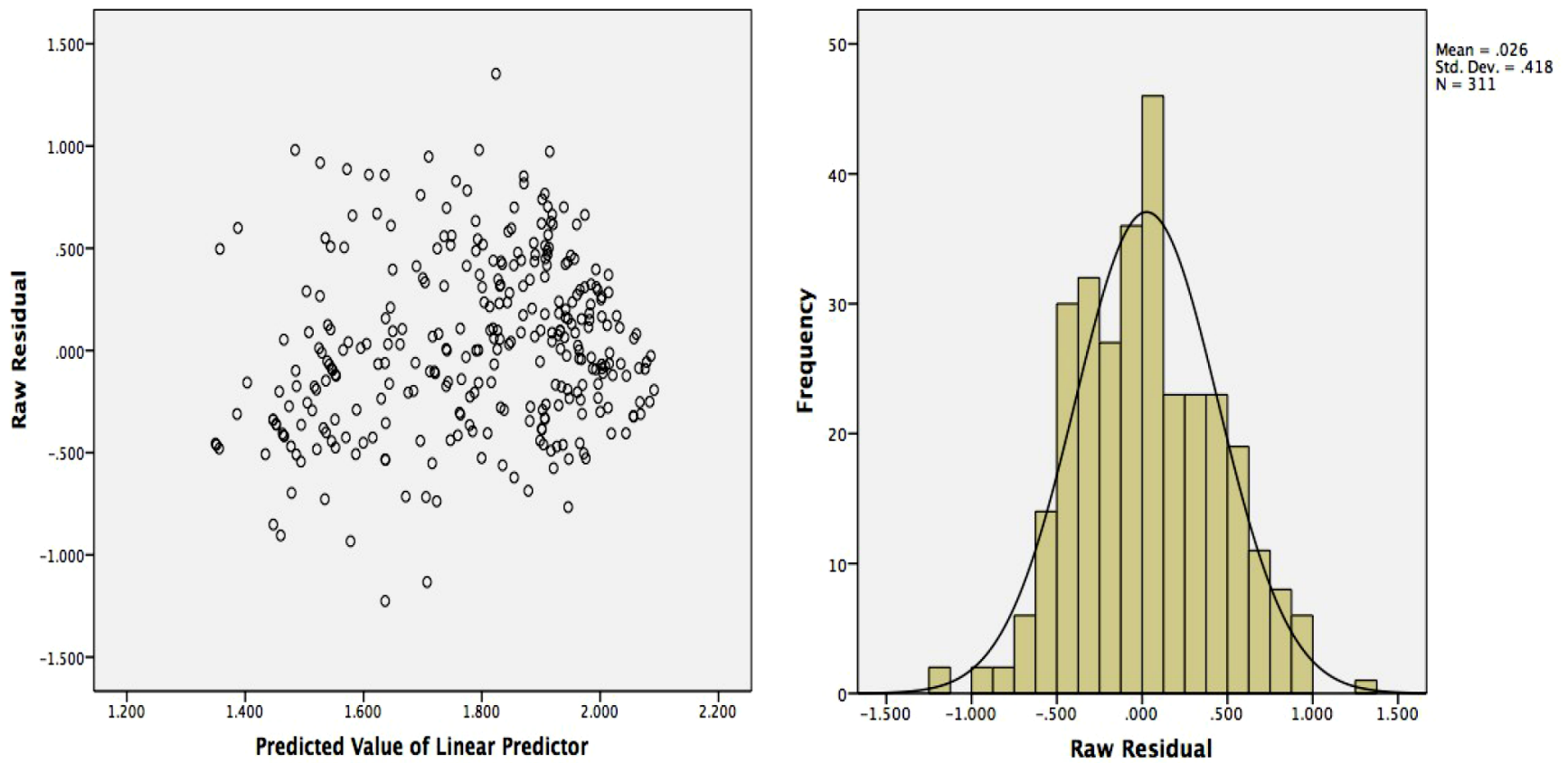

Figure 4. Distribution of residuals, with normal fit. Note: one-sample Kolmogorov-Smirnov test - the maximum absolute difference between observed frequency of residuals and normal distribution $=0.044 ; p=0.200$.

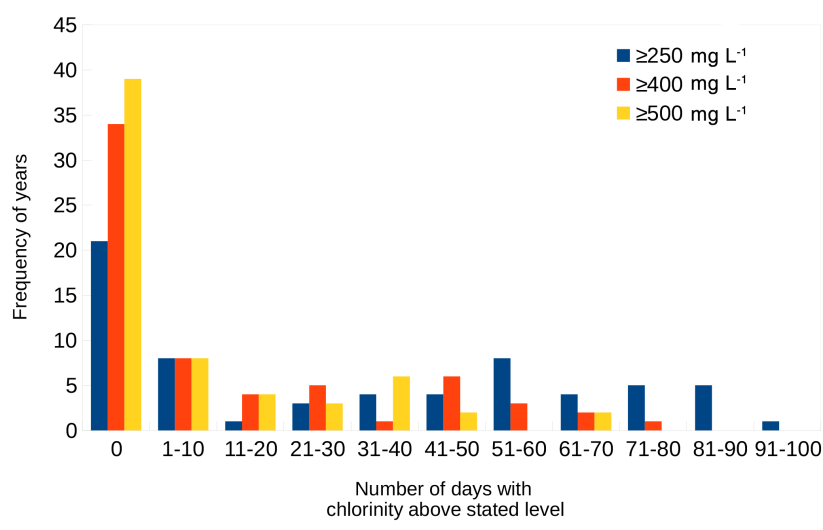

Figure 5. Frequency distribution of years, classified by number of days with high chlorinity.

However, the complete model is probabilistic, with a frequency distribution of residuals around these mean predictions, as illustrated in Fig. 4, so it is important to use these probabilistic predictions in order to understand the probability of encountering long-duration intense intrusions under the discharge characteristics of the various years in the sample.

\subsection{Discharge and intrusions}

This model, with its known frequency distribution of residuals (Fig. 4), is therefore used to simulate salinity intrusions. These simulations follow Monte Carlo methods, in which the frequency distribution of residuals is repeatedly sampled, in conjunction with the other parameters of Eq. (2), in order to identify the probability that intrusions of given intensities and durations will occur. The results are first illustrated in detail for 1962, the year with the longest-duration intense intrusion on record. Figure 6 reveals the frequencies with which salinities of 250,400 and $500 \mathrm{mg} \mathrm{L}^{-1}$ for different lengths of time were observed in the simulations. Superimposed on the frequencies is a Weibull distribution, fitted by least squares. The most common intrusion of $250 \mathrm{mg} \mathrm{L}^{-1}$ lasts for 74 days, but even intrusions of at least 91 days occur with a probability of 0.05 , and intrusions of at least 97 days occur with a probability of 0.01 . An intrusion of at least 73 days is as likely to occur as not. The most common intrusion of $400 \mathrm{mg} \mathrm{L}^{-1}$ lasts 67 days, while intrusions of at least 77 days have a probability of occurring of 0.05 , and those of at least 85 days occur with a probability of 0.01 . Intrusions of 55 days are as likely to occur as not. The most common length of an intrusion of $500 \mathrm{mg} \mathrm{L}^{-1}$ is 67 days, but intrusions of 69 days occur with a probability of 0.05 , and those of 77 days occur with a probability of 0.01 . Intrusions of 47 days are as likely to occur as not. These are the model predictions of the duration of salinity intrusions for years in which the discharge characteristics are those of 1962.

Similar calculations have been made to determine the probability of occurrence of various durations of intrusions of 250,400 and $500 \mathrm{mg} \mathrm{L}^{-1}$ for every other year. Table 2 provides the simple correlations between the simulated frequencies of three durations (30, 50 and 60 days) and a variety of characteristics of discharge for all the years of record. The 

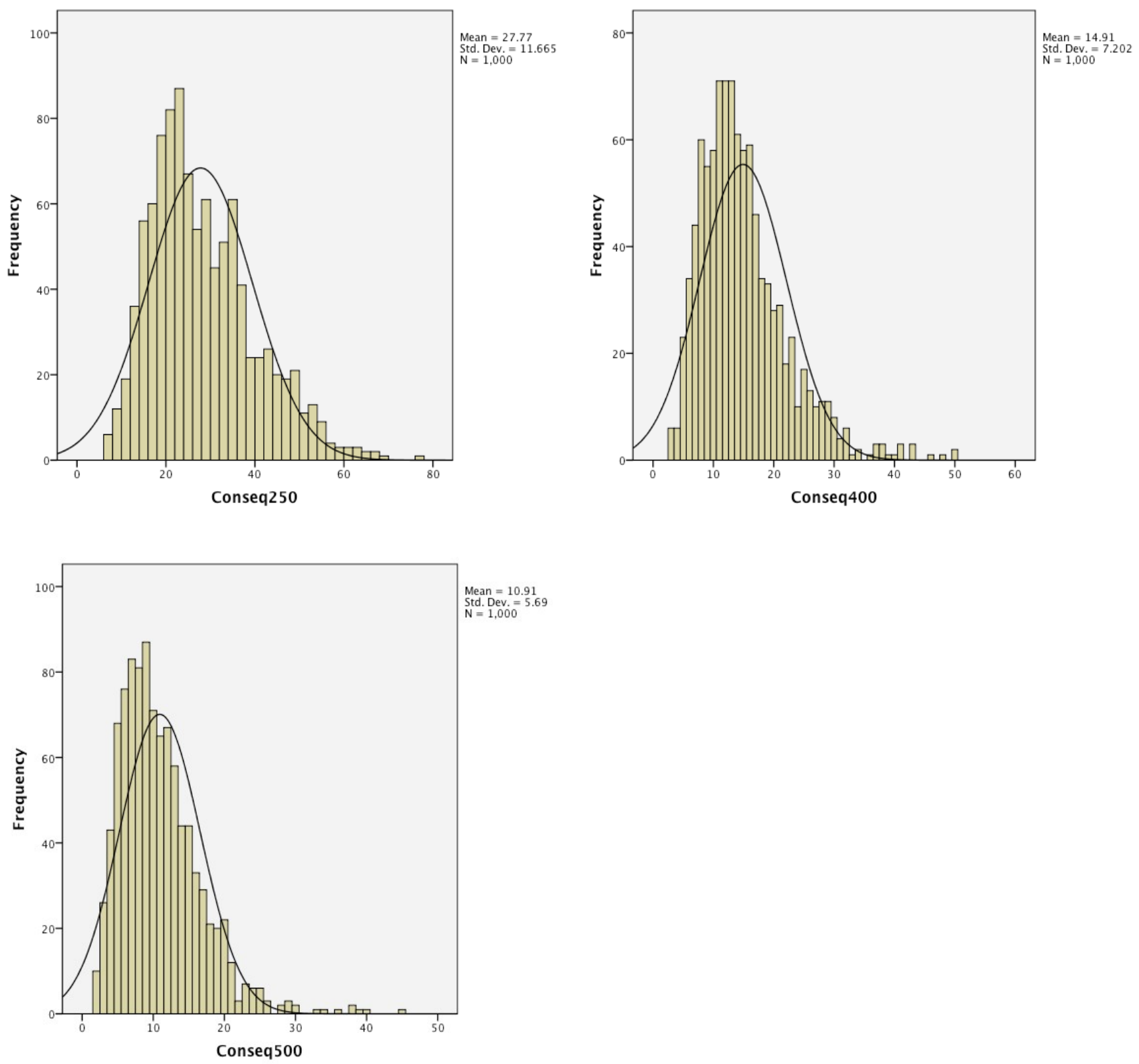

Figure 6. Frequency distributions of numbers of consecutive days with chlorinity above 250 (upper left), 400 (upper right) and $500 \mathrm{mg} \mathrm{L}^{-1}$ (lower left), fitted with Weibull distributions for 1962.

probability that in a year chlorinity $\geq 250 \mathrm{mg} \mathrm{L}^{-1}$ for at least 30 days consecutively is correlated with a variety of measures of low flow, especially the number of days for which discharge $\leq 12000,10000$ or $8000 \mathrm{~m}^{3} \mathrm{~s}^{-1}$. However, the probabilities of longer-duration intrusions of $\geq 250 \mathrm{mg} \mathrm{L}^{-1}$ and the probabilities of higher salinity intrusions are best predicted by measures of the number of days for which discharge $\leq 8000 \mathrm{~m}^{3} \mathrm{~s}^{-1}$. Across all the durations and chlorinity levels, the best predictor of the probabilities of durationchlorinity pairs is the maximum number of consecutive days for which discharge falls below $8000 \mathrm{~m}^{3} \mathrm{~s}^{-1}$. Worryingly for planners, no measures of discharge before the event predict long-duration, high-intensity intrusions.

Figure 7 reveals in more detail how the probability of observing duration-chlorinity pairs depends on the duration of discharge below $8000 \mathrm{~m}^{3} \mathrm{~s}^{-1}$. These graphs are the first result at which this method is aimed.

The upper graph in Fig. 7 illustrates how the probability of 30-, 40- and 50-day intrusions of $\geq 250 \mathrm{mg} \mathrm{L}^{-1}$ in a year varies in relation to the number of consecutive days in that year in which discharge $\leq 8000 \mathrm{~m}^{3} \mathrm{~s}^{-1}$. Only if there are at least 20 consecutive days in a year with discharge 
Table 2. Correlations between probabilities of chlorinity above stated levels for stated lengths of time and selected discharge characteristics, annual scale.

\begin{tabular}{|c|c|c|c|c|c|c|c|c|c|c|}
\hline \multirow[t]{2}{*}{ Indicator } & & \multicolumn{3}{|c|}{ Chlorinity $\geq 250$ for $\geq$ (days) } & \multicolumn{3}{|c|}{ Chlorinity $\geq 400$ for $\geq$ (days) } & \multicolumn{3}{|c|}{ Chlorinity $\geq 500$ for $\geq$ (days) } \\
\hline & & 30 & 50 & 60 & 30 & 50 & 60 & 30 & 50 & 60 \\
\hline Aug-May & avg. $Q_{\mathrm{d}}$ & - & - & - & - & - & - & - & - & - \\
\hline Dec-Mar & avg. $Q_{\mathrm{d}}$ & $-^{\mathrm{a}}$ & - & - & - & - & - & - & - & - \\
\hline Nov & avg. $Q_{\mathrm{d}}$ & - & - & - & - & - & - & - & - & - \\
\hline Dec & avg. $Q_{\mathrm{d}}$ & - & - & - & - & - & - & - & - & - \\
\hline Dec-Feb & avg. $Q_{\mathrm{d}}$ & $-^{\mathrm{a}}$ & - & - & - & - & - & - & - & - \\
\hline Jan-Feb & avg. $Q_{\mathrm{d}}$ & $-^{\mathrm{a}}$ & - & - & - & - & - & - & - & - \\
\hline No days & $Q_{\mathrm{d}}<16000$ & + & + & + & + & + & + & + & + & + \\
\hline $\mathrm{NC}$ days & $Q_{\mathrm{d}}<16000$ & + & + & + & + & + & + & + & + & + \\
\hline Avg. flow & $Q_{\mathrm{d}}<16000$ & $-^{\mathrm{a}}$ & - & - & - & - & - & - & - & - \\
\hline No days & $Q_{\mathrm{d}}<14000$ & + & + & + & + & + & + & + & + & + \\
\hline $\mathrm{NC}$ days & $Q_{\mathrm{d}}<14000$ & $+^{\mathrm{a}}$ & + & + & + & + & + & + & + & + \\
\hline Avg. flow & $Q_{\mathrm{d}}<14000$ & $-\mathrm{b}$ & - & - & - & - & - & - & - & - \\
\hline No days & $Q_{\mathrm{d}}<12000$ & + & + & + & + & + & + & + & + & + \\
\hline $\mathrm{NC}$ days & $Q_{\mathrm{d}}<12000$ & $+{ }^{c}$ & $+^{\mathrm{a}}$ & + & $+^{\mathrm{a}}$ & + & + & + & + & + \\
\hline Avg. flow & $Q_{\mathrm{d}}<12000$ & $-^{\mathrm{c}}$ & $-^{\mathrm{a}}$ & - & $-^{\mathrm{a}}$ & - & - & - & - & - \\
\hline No days & $Q_{\mathrm{d}}<10000$ & $+^{c}$ & $+^{\mathrm{a}}$ & + & + & + & + & + & + & + \\
\hline NC days & $Q_{\mathrm{d}}<10000$ & $+{ }^{\mathrm{d}}$ & $+{ }^{b}$ & $+^{\mathrm{a}}$ & $+{ }^{b}$ & + & + & $+^{\mathrm{a}}$ & + & + \\
\hline Avg. flow & $Q_{\mathrm{d}}<10000$ & $-^{\mathrm{c}}$ & $-{ }^{\mathrm{a}}$ & - & $-\mathrm{b}$ & - & - & $-{ }^{\mathrm{a}}$ & - & - \\
\hline No days & $Q_{\mathrm{d}}<8000$ & $+^{c}$ & $+^{\mathrm{d}}$ & $+^{\mathrm{c}}$ & $+^{\mathrm{d}}$ & $+^{b}$ & $+^{\mathrm{a}}$ & $+^{\mathrm{c}}$ & $+^{\mathrm{a}}$ & + \\
\hline NC days & $Q_{\mathrm{d}}<8000$ & $+^{c}$ & $+^{\mathrm{d}}$ & $+^{\mathrm{d}}$ & $+{ }^{\mathrm{d}}$ & $+^{\mathrm{c}}$ & $+{ }^{\mathrm{b}}$ & $+{ }^{\mathrm{d}}$ & $+{ }^{\mathrm{b}}$ & $+^{\mathrm{a}}$ \\
\hline
\end{tabular}

Note: $Q_{\mathrm{d}}<16000,12000,10000$ or 8000 refers to the period from the date of the first discharge in the river year less than 16000 (or 12000 , or 8000 , respectively) $\mathrm{m}^{3} \mathrm{~s}^{-1}$ to the date of the last discharge in the river year less than 16000 (or 12000 , or 8000 ) $\mathrm{m}^{3} \mathrm{~s}^{-1}$. No days: total number of days with discharge less than 16000 (or 12000 , or 8000$)^{3} \mathrm{~m}^{-1}$. Avg flow: average discharge in entire period. NC: number of consecutive days with discharge less than 16000 (or 12000 , or 8000 ) $\mathrm{m}^{3} \mathrm{~s}^{-1}$.

$\leq 8000 \mathrm{~m}^{3} \mathrm{~s}^{-1}$ does the probability of at least 30 days with chlorinity $\geq 250 \mathrm{mg} \mathrm{L}^{-1}$ rise above 0.025 . As the number of consecutive days in a year with discharge $\leq 8000 \mathrm{~m}^{3} \mathrm{~s}^{-1}$ rises from 0 to 20 , the probability of at least 30 days with chlorinity $\geq 250 \mathrm{mg} \mathrm{L}^{-1}$ rises to $0.55-0.9$. When the number of consecutive days in a year with discharge $\leq$ $8000 \mathrm{~m}^{3} \mathrm{~s}^{-1}$ rises to 30 and then to $40-50$, the probability of at least 30 days with chlorinity $\geq 250 \mathrm{mg} \mathrm{L}^{-1}$ is 0.9 and 0.99 , respectively. Longer-duration intrusions of chlorinity $\geq 250 \mathrm{mg} \mathrm{L}^{-1}$ are also closely related to the number of consecutive days with discharge $\leq 8000 \mathrm{~m}^{3} \mathrm{~s}^{-1}$. If in a year the number of such days is less than eight, then 50- or 60-day intrusions of chlorinity $\geq 250 \mathrm{mg} \mathrm{L}^{-1}$ have a probability lower than 0.2; when the number of such days is between 9 and 30 , then the probability of 50 days of $\geq 250 \mathrm{mg} \mathrm{L}^{-1}$ lies between 0.1 and 0.5 and for 60 days it lies between 0.1 and 0.3 .

The central graph in Fig. 7 illustrates how intrusions of chlorinity $\geq 400 \mathrm{mg} \mathrm{L}^{-1}$ vary in relation to the number of consecutive days in a year with discharge $\leq 8000 \mathrm{~m}^{3} \mathrm{~s}^{-1}$, while the lower graph illustrates the same information for intrusions of $\geq 500 \mathrm{mg} \mathrm{L}^{-1}$. In both cases, the probability of 30-day intrusions rises linearly as the number of consecutive low discharge days increases. In both cases, too, the probability of a longer intrusion (50 or 60 days) is less than 0.1 unless the number of consecutive days in a year with discharge $\leq 8000 \mathrm{~m}^{3} \mathrm{~s}^{-1}$ exceeds 30 . In the 2 years in which more than 44 consecutive days exhibited discharge $\leq 8000 \mathrm{~m}^{3} \mathrm{~s}^{-1}$, the probability of 50-day or 60-day, chlorinity $\geq 400 \mathrm{mg} \mathrm{L}^{-1}$ intrusions lie between 0.5 and 0.7 or between 0.25 and 0.5 , respectively. The probability of 50-day or 60 -day, $\geq 500 \mathrm{mg} \mathrm{L}^{-1}$ intrusions is a little lower; even so, the probability of 50-day intrusions of chlorinity $\geq 500 \mathrm{mg} \mathrm{L}^{-1}$ is 0.25 or 0.47 if a year has 44 or 50 , respectively, consecutive days with discharge $\leq 8000 \mathrm{~m}^{3} \mathrm{~s}^{-1}$. This event occurred twice in the 64-year-long record.

This information is summarised in Table 3.

\subsection{Impact of Three Gorges Dam, SNWTP and local abstractions on intrusions}

The net effect of the three modifications is to reduce the discharge of the Yangtze River at the estuary for most of the year (Fig. 3). The operations of the Three Gorges Dam cause net decreases in discharge when it is being filled (October and early November), but nil effects or net increases throughout the rest of the year, including in the periods of lowest flow (December-February). However, these effects are offset by abstractions for the middle and eastern routes of the SNWTP and by abstractions in the delta region. In aggregate, discharge is reduced throughout the year, except when nor- 

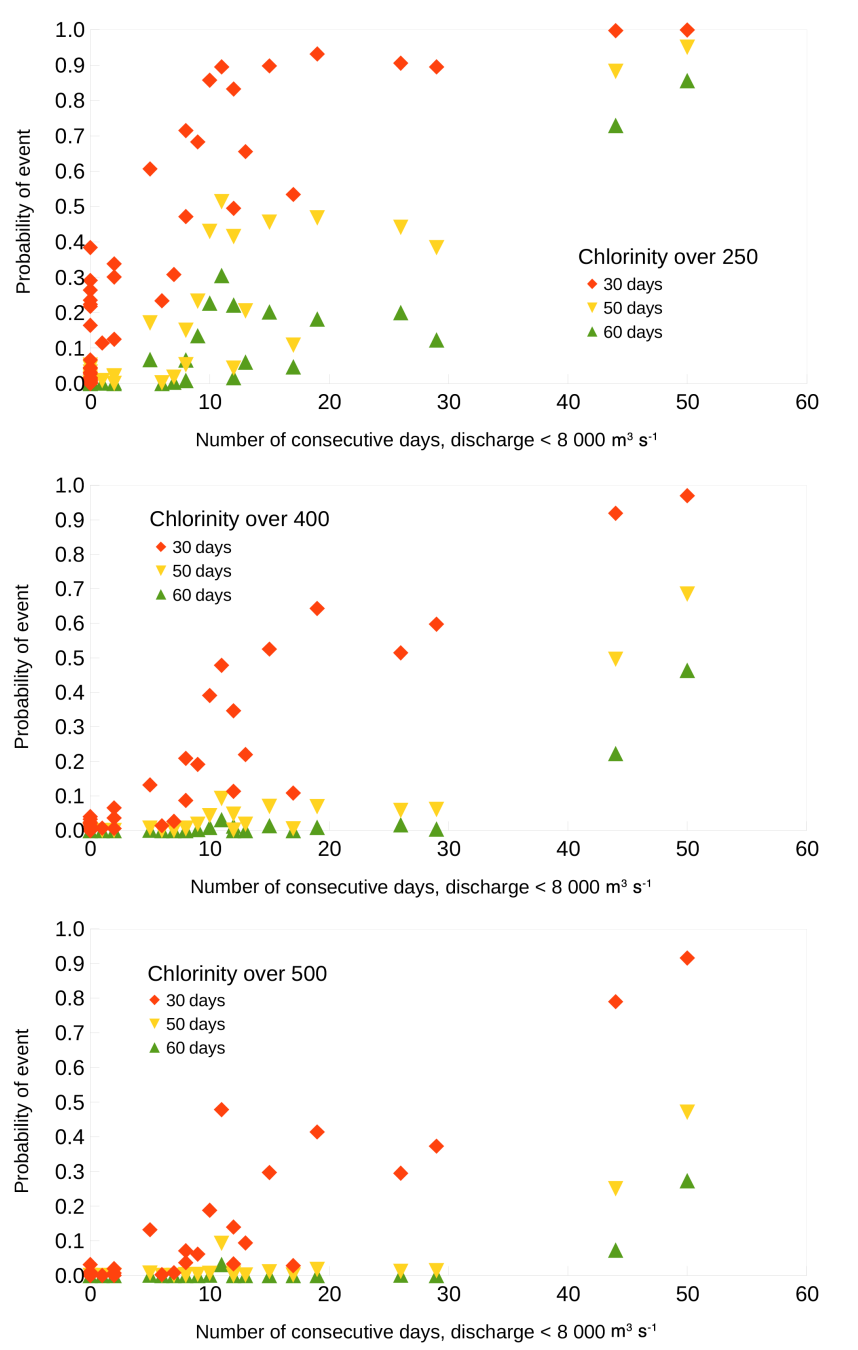

Figure 7. Relationship between long-duration, high-intensity intrusions and duration of low discharges.

mal operating rules raise discharges from the Three Gorges Dam above inflows (in April and May).

The consequence is an increase in the risk of long-duration salt intrusions. We illustrate the calculations by examining the probabilities of intrusions of chlorinity $\geq 250 \mathrm{mg} \mathrm{L}^{-1}$ for 30,50 and 60 days (Table 4 ). The probability, calculated over 1024 simulations for the discharges observed in 1950-2014 and the abstractions identified in Fig. 3, of a 30-day intrusion of $\geq 250 \mathrm{mg} \mathrm{L}^{-1}$ was 0.25 under then current conditions, would rise to 0.40 under conservative rules by $2030-2035$ and to 0.57 under normal rules. Likewise, the probabilities of 60-day intrusions of $\geq 250 \mathrm{mg} \mathrm{L}^{-1}$ rise from 0.05 to 0.14 and 0.28 under the three conditions.

More light is shed on the risk of intrusions in Fig. 8. These graphs reveal the proportion of years in which the probability of an intrusion of chlorinity $\geq 250 \mathrm{mg} \mathrm{L}^{-1}$ for 30,50 and 60 days lies in the specified range. The upper graph indicates that 0.55 of years have a probability of less than 0.1
Table 3. Probability of intrusion duration and intensity in relation to length of periods of low discharge.

\begin{tabular}{|c|c|c|c|c|}
\hline \multirow[t]{2}{*}{$\begin{array}{l}\text { Duration } \\
\text { of period } \\
\text { discharge } \\
\leq 8000 \mathrm{~m}^{3} \mathrm{~s}^{-1}\end{array}$} & \multirow[t]{2}{*}{$\begin{array}{r}\text { No. of years } \\
\text { with this } \\
\text { duration } \\
\text { discharge }\end{array}$} & \multicolumn{3}{|c|}{$\begin{array}{l}\text { Average probability } \\
\text { of intrusion } \\
\geq 250 \mathrm{mg} \mathrm{L}^{-1} \text { lasting } \\
\end{array}$} \\
\hline & & 30 days & 50 days & 60 days \\
\hline 0 days & 42 & 0.050 & 0.004 & 0.001 \\
\hline 1-7 days & 7 & 0.289 & 0.034 & 0.011 \\
\hline 8-17 days & 10 & 0.703 & 0.261 & 0.129 \\
\hline 19-29 days & 3 & 0.910 & 0.431 & 0.168 \\
\hline \multirow[t]{3}{*}{ 44-50 days } & 2 & 0.998 & 0.916 & 0.792 \\
\hline & & \multicolumn{3}{|c|}{$\begin{array}{l}\text { Average probability of intrusion } \\
\quad \geq 400 \mathrm{mg} \mathrm{L}^{-1} \text { lasting }\end{array}$} \\
\hline & & 30 days & 50 days & 60 days \\
\hline 0 days & 42 & 0.003 & 0.000 & 0.000 \\
\hline 1-7 days & 7 & 0.041 & 0.001 & 0.000 \\
\hline $8-17$ days & 10 & 0.267 & 0.030 & 0.007 \\
\hline 19-29 days & 3 & 0.585 & 0.062 & 0.010 \\
\hline \multirow[t]{3}{*}{$44-50$ days } & 2 & 0.944 & 0.590 & 0.343 \\
\hline & & \multicolumn{3}{|c|}{$\begin{array}{l}\text { Average probability of intrusion } \\
\geq 500 \mathrm{~m} \mathrm{~L} \mathrm{~L}^{-1} \text { lasting }\end{array}$} \\
\hline & & 30 days & 50 days & 60 days \\
\hline 0 days & 42 & 0.001 & 0.000 & 0.000 \\
\hline 1-7 days & 7 & 0.024 & 0.001 & 0.000 \\
\hline 8-17 days & 10 & 0.143 & 0.012 & 0.003 \\
\hline 19-29 days & 3 & 0.361 & 0.014 & 0.000 \\
\hline 44-50 days & 2 & 0.853 & 0.360 & 0.173 \\
\hline
\end{tabular}

Table 4. Probability of intrusions of $\geq 250 \mathrm{mg} \mathrm{L}^{-1}$ under current conditions, normal operating rules and conservative operating rules for the Three Gorges Dam, South-North Water Transfer Project and local abstractions.

\begin{tabular}{|c|c|c|c|}
\hline & \multicolumn{3}{|c|}{$\begin{array}{c}\text { Average probability of intrusion } \\
\geq 250 \mathrm{mg} \mathrm{L}^{-1} \text { lasting }\end{array}$} \\
\hline & 30 days & 50 days & 60 days \\
\hline Current conditions & 0.248 & 0.096 & 0.055 \\
\hline Conservative rules & 0.399 & 0.200 & 0.140 \\
\hline Normal rules & 0.569 & 0.361 & 0.278 \\
\hline
\end{tabular}

that an intrusion of $\geq 250 \mathrm{mg} \mathrm{L}^{-1}$ will last at least 30 days under then-current historical discharges. Under conservative operating rules, that proportion falls to 0.42 , while 0.42 of years have a probability of at least 0.5 of an intrusion of $\geq 250 \mathrm{mg} \mathrm{L}^{-1}$ lasting at least 30 days. Under normal operating rules, 0.56 of years have a probability of at least 0.5 of an intrusion of $\geq 250 \mathrm{~m} \mathrm{~L}^{-1}$ lasting at least 30 days. Similar changes in the probabilities of intrusions are revealed by the central (intrusions of at least 50 days) and lower (intrusions of at least 60 days) graphs. 

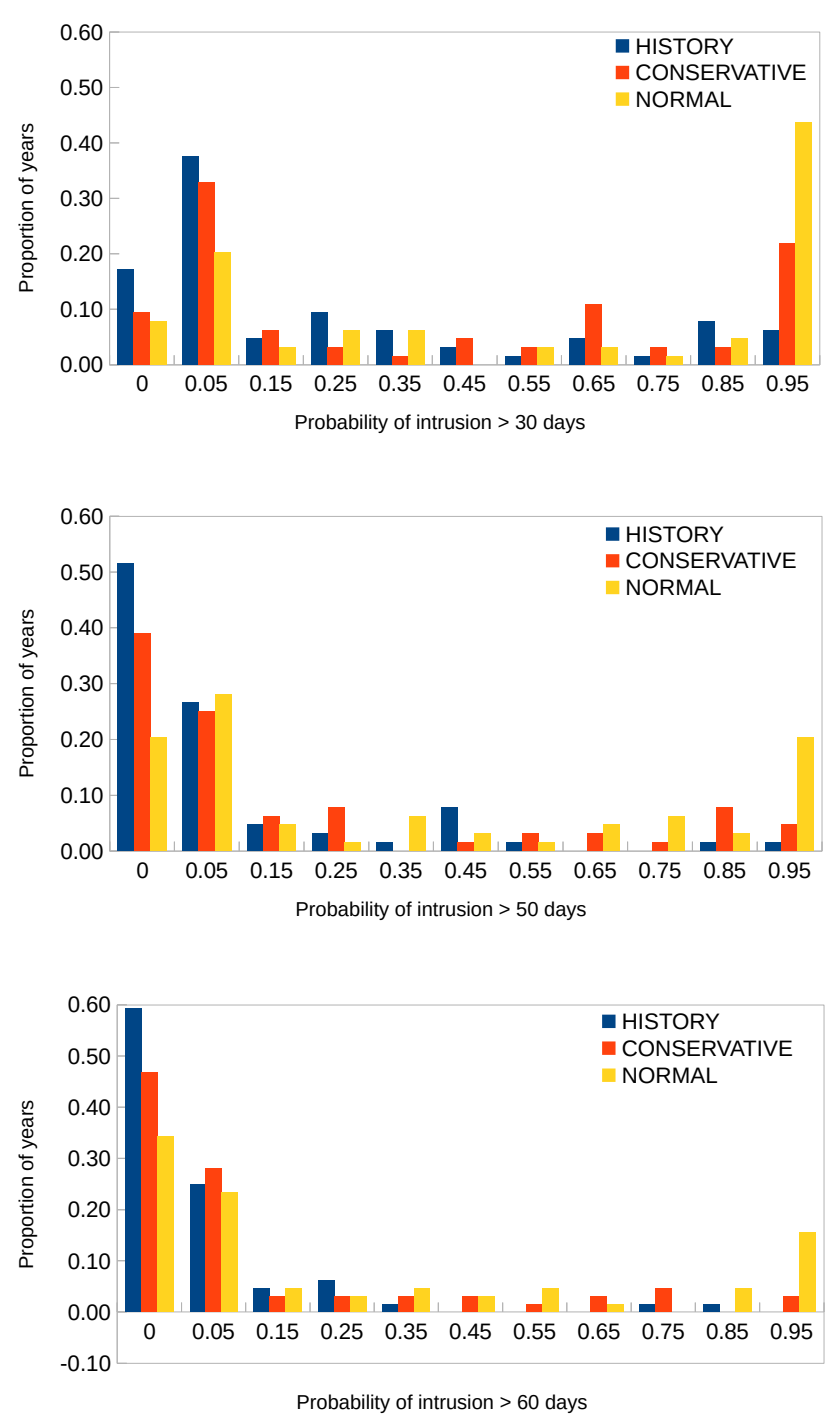

Figure 8. Impact of normal and conservative operating rules for the Three Gorges Dam, South-North Water Transfer Project and local abstractions on probabilities of intrusions of 30, 50 and 60 days.

\section{Discussion}

Unlike previous studies of intrusions of saltwater into the estuary of the Yangtze River, this paper has sought to identify the conditions under which intense intrusions of long duration occur. Constrained by both the shortage of the discharge record and the paucity of observations of discharge and salinity, the paper has constructed a model of the relationship between salinity and discharge and then employed Monte Carlo simulation methods to reconstruct the probability of observing intrusions of differing intensities and durations in relation to discharge. The model predicts that the duration of intrusions with chlorinity $\geq 250 \mathrm{mg} \mathrm{L}^{-1}$ increases as the number of consecutive days with discharge $\leq 12000 \mathrm{~m}^{3} \mathrm{~s}^{-1}$ increases; consecutive days of lower dis- charges $\left(\leq 8000 \mathrm{~m}^{3} \mathrm{~s}^{-1}\right)$ predict the duration of intrusions with chlorinity $\geq 400$ or $500 \mathrm{mg} \mathrm{L}^{-1}$.

In 51 of the 64 years analysed, the probability of an intrusion of at least 30 days at chlorinity $\geq 250 \mathrm{mg} \mathrm{L}^{-1}$ is greater than 1 in 1000; in 37 years, it is greater than 1 in 100; and in 15 years it is greater than 1 in 10 . In 26 years, the probability of an intrusion of at least 60 days at $\geq 250 \mathrm{mg} \mathrm{L}^{-1}$ is greater than 1 in 1000; in 17 years is greater than 1 in 100; and in 10 years is greater than 1 in 10 .

In 26 years, the probability of an intrusion of at least 30 days at chlorinity $\geq 500 \mathrm{mg} \mathrm{L}^{-1}$ is greater than 1 in 1000 , in 19 years it is greater than 1 in 100; and in 10 years it is greater than 1 in 10 . The most extreme event analysed in this paper, an intrusion of $\geq 500 \mathrm{mg} \mathrm{L}^{-1}$ for more than 60 days occurs with a probability greater than 1 in 1000 in 6 years and is greater than 1 in 100 and 1 in 10 in only 1 year.

Existing estimates in the literature of discharges at which salinity intrusions occur in the Yangtze Estuary are point estimates: they seek to identify a discharge below which intrusions are likely and above which intrusions are unlikely. Serious intrusions occurred near the Chenhang Reservoir in 1978-1979, 2001-2002 and 2006-2007, when the maximum average monthly discharges in January and February were 7103,10165 and $11777 \mathrm{~m}^{3} \mathrm{~s}^{-1}$, respectively, leading Chen et al. (2013) to suggest that the critical discharge into the estuary is at least $11777 \mathrm{~m}^{3} \mathrm{~s}^{-1}$. Gu and Yue (2004) suggested that a monthly mean Datong discharge of $11000 \mathrm{~m}^{3} \mathrm{~s}^{-1}$ was critical and, Wang et al. (2008) identified $13000 \mathrm{~m}^{3} \mathrm{~s}^{-1}$. Data in $\mathrm{Li}$ et al. (2014) demonstrate that mean salinity levels near Qingcaosha are a negative exponential function of discharge at Datong 7 days earlier; at discharges lower than $11500 \mathrm{~m}^{3} \mathrm{~s}^{-1}$, mean salinity exceeds $250 \mathrm{mg} \mathrm{L}^{-1}$. These results are broadly consistent with those reported in this paper, though the estimate of Wang et al. (2008) is high. However, they are misleading in the sense that there is no critical discharge: at all discharges $\leq 16000 \mathrm{~m}^{3} \mathrm{~s}^{-1}$, the lower the discharge and the longer that low flow persists, the higher the probability of longer and more intense salt intrusions. The relationship between discharge and salinity is probabilistic as well as continuous.

The second principal result of the paper is the measurement of the effect of the Three Gorges Dam, the SNWTP and local water abstractions in the delta on the probability of long-duration intrusions. The calculations were presented for intrusions of chlorinity $\geq 250 \mathrm{mg} \mathrm{L}^{-1}$, since this is the legal standard for drinking water in China and, given the absence of desalinisation treatment in Shanghai, the de facto standard for water intakes into treatment plants. Our results indicate that, for a randomly selected year of discharge history from the period 1950-2014, the probability of an intrusion rises from 0.25 (30 days) or 0.05 (60 days) to $0.40-0.57$ or $0.14-0.28$ (depending on the operating rules), respectively. The proportion of years for which the probability of an intrusion exceeds 0.50 rises from $0.22,0.05$ and 0.03 for $30-, 50$ - 
and 60-day intrusions, respectively, to $0.42-0.56,0.20-0.36$ and $0.13-0.27$, depending on the operating rules.

Others have also pointed out that the Three Gorges Dam, the SNWTP and local abstractions will affect the probability of salt intrusions into the Yangtze Estuary. In general, the operations of the Three Gorges Dam tend to reduce the probability of saline intrusions, since under normal operating rules the reservoir discharges more than inflow during the periods of lowest natural discharge in December-February (An et al., 2009). However, the SNWTP and local abstractions both reduce discharge into the estuary, tending to create a "high likelihoods" of saltwater intrusions in December-February of a dry year and in January and February of a normal year (Chen et al., 2013); likewise, Zhang et al. (2003, 2012) estimate the effects on discharge of local abstractions, though without calculating their impacts on the probability of an intrusion of saltwater. None of these, however, has calculated the changes in the probability of intrusions caused by these abstractions nor sought to apply their methods to the entire historical record of discharge and much less to identify the likely duration of saline intrusions.

The literature does identify other conditions besides discharge that affect the occurrence of salt intrusions, notably tide and wind conditions (Kuang et al., 2009; Li et al., 2012; Liu et al., 2013; Xue et al., 2009; Zhang et al., 2011). As noted in Appendix A, Zhang et al. (2012) also demonstrate that water abstractions from the Yangtze River below the gauging station at Datong are a significant proportion of total discharge, especially if years of relatively low discharge are also years of low rainfall in the estuary region. These are factors that an analysis of discharge data for the entire period 1950-2014 cannot take into account. In addition, there are concerns that rainfall patterns in the Yangtze Basin may be changing under the influence of climate change (Jiang et al., 2008; Tao et al., 2012), which may alter the discharge characteristics of the river; furthermore, sea levels off the Yangtze Estuary have been rising and this will have effects similar to a reduction in discharge (Cai et al., 2009). The paper has not accounted for these factors.

Finally, we should comment on our choice of method. The risk of using a statistical model is that it works in the calibration period but fails outside that time; we sought to minimise this risk by calibrating the model with data from five separate years from 1979 to 2007 and spanning discharges in the entire range $6000-16000 \mathrm{~m}^{3} \mathrm{~s}^{-1}$. No lower discharges have ever been observed and at higher discharges saltwater intrusions are unlikely. The principal change that is likely to modify the observed relationship between salinity and discharge is an alteration in the morphology of the channel - deepening it or widening it, for example. Our calculations and predictions are therefore subject to the proviso that such changes in the morphology of the estuary do not occur. If the morphology of the estuary is not changed, then the discharge conditions under which saltwater from the north of Chongming Island (the north branch) spills over into the south branch will remain constant, and the calibrated relationship between discharge and saltwater intrusions will continue to hold.

\section{Conclusion}

This paper has demonstrated a new method for calculating the probability of occurrence of long-duration salt intrusions of specified chlorinity. The method shows that the relationship between discharge and the intensity and duration of salinity intrusions is probabilistic and continuous. At discharges $\leq 16000 \mathrm{~m}^{3} \mathrm{~s}^{-1}$, the lower the discharge and the longer that low flow persists, the higher the probability of longer and more intense salt intrusions. Combining this result with the known frequency of periods of low discharge during the period 1950-2014, the paper calculates that saline intrusions (chlorinity $\geq 250 \mathrm{mg} \mathrm{L}^{-1}$ ) of at least 30 days occur with $p \geq 0.01$ in 37/64 years and with $p \geq 0.1$ in $15 / 64$ years. Saline intrusions (chlorinity $\geq 250 \mathrm{mg} \mathrm{L}^{-1}$ ) of at least 60 days occur with $p \geq 0.01$ in 17/64 years and with $p \geq 0.1$ in 10 years. Intrusions that can disrupt the supply of water to Shanghai's residents are not rare events.

Furthermore, they will become even less rare as the Three Gorges Dam, the SNWTP and local water abstractions in the delta begin to affect discharge into the Yangtze Estuary. The proportion of years for which an intrusion is more likely than not rises from $0.22,0.05$ and 0.03 for $30-, 50$ and 60-day intrusions, respectively, to $0.42-0.56,0.20-0.36$ and $0.13-0.27$, depending on the operating rules of the three projects. However, these predictions do not account for ongoing changes in precipitation or rises in sea level, both associated with climate change. If climate change does not have the effect of increasing discharge in the winter months, then operating rules will have to be revised during years of low discharge or Shanghai will have to find alternative sources of water to prevent the disruptions to supply that these calculations predict. 
Appendix A: Data sources and assumptions: dams and diversions

\section{A1 Dams}

The largest dam on the Yangtze is the Three Gorges Dam. Other dams are being built above Three Gorges, but we assume that any effects of their operation on discharge at Datong will be regulated through the Three Gorges Dam. There are also dams on other tributaries which join the Yangtze below the Three Gorges Dam, but their effect is not separately considered here, though it is present in the discharge record.

Chen et al. (2001) describe the plans for the operation of the Three Gorges Dam. The reservoir is planned to store water from October each year, tending to decrease flows below the dam. In a dry year, the water storage process may have to be extended to November. Then, during the dry season (December-April), the water level in the reservoir will need to be dropped to meet the needs of the hydropower plant. The plan is that minimum water levels will be attained at the end of September. Guo et al. (2011; their Figs. 3, 8) provide more details: in June, July and August, the reservoir water level is maintained at $145 \mathrm{~m}$ a.s.l. to provide for flood control during the wet season. In October, the water level is raised to $175 \mathrm{~m}$ a.s.l., the planned maximum level, and it is maintained at as high a level as possible (and above $155 \mathrm{~m}$ a.s.l. to facilitate navigation) until the end of April, when it is again reduced to $145 \mathrm{~m}$ a.s.l. According to Zhang et al. (2012, Table 3), the Three Gorges Dam holds $\sim 21.5 \times 10^{9} \mathrm{~m}^{3}$ more water at its planned maximum level than at its planned minimum level.

Given estimates that it takes 14 days for water to flow from the dam site to Datong, Zhang et al. (2012) estimate that the reservoir's operation would be as follows: in a dry year (e.g. 2001-2002) fill from 15 September to 31 October and in an extremely dry year (e.g. 1978-1979) fill from 1 September to 15 November.

We assume the following. Under normal rules, the reservoir is filled in October, which reduces flow at Datong from 15 October to 14 November by $8000 \mathrm{~m}^{3} \mathrm{~s}^{-1}$. Under conservative rules (corresponding to dry-year operations) the reservoir is filled from mid-September through to the end of October, which reduces discharge at Datong from 29 September to 14 November by $5400 \mathrm{~m}^{3} \mathrm{~s}^{-1}$. Following Guo et al. (2011, their Fig. 8), in normal operation, the reservoir is assumed to maintain its maximum water level until the end of January, which will have no effect on discharge at Datong until 14 February, and then to progressively discharge at rates above inflows from February to the end of April, increasing discharge at Datong from 14 February to 14 May by 900 , 1800 and $2700 \mathrm{~m}^{3} \mathrm{~s}^{-1}$ in each 30 -day period; in May, the reservoir level is reduced to $145 \mathrm{~m}$ a.s.l., which implies an increase in discharge at Datong from 14 May to 14 June of $2700 \mathrm{~m}^{3} \mathrm{~s}^{-1}$. For the remainder of the year there is no net storage or release of water. A more conservative rule is for the reservoir to discharge at constant rates above inflow from December to August, which increases discharge at Datong from 15 December to 14 August by $916 \mathrm{~m}^{3} \mathrm{~s}^{-1}$. For the remainder of the year, there is no net storage or release of water.

Zhang et al. (2012) state that the dam first began to affect discharges in 2006-2007, when experiments began to fill it. These experiments continued until 2010. Thereafter, the dam has functioned normally. Therefore, the assumed modifications to discharge at Datong are not applied to years 20102011 onwards.

\section{A2 South-North Water Transfer Project}

The South-North water diversion project (SNWTP) project involves three routes: a western route, a middle route and a third route, taking water from the Yangtze to northern China. The western route is still in the planning stages and the volume of water to be diverted is still uncertain; it will not be operation until at least 2020. It is not considered any further here, though it can be assumed that it will exacerbate the situation described in this paper. The central and the eastern routes are now operating, however.

The eastern route is planned to transfer 8.9, 10.6 and 14.8 billion $\mathrm{m}^{3} \mathrm{yr}^{-1}$ in successive stages, according to official sources (see http://www.nsbd.gov.cn). However, a recent report (http://news.dichan.sina.com.cn/2014/01/14/1015543. html) indicates that only about 3.6 billion $\mathrm{m}^{3} \mathrm{yr}^{-1}$ is currently being delivered to northern provinces. Wet seasons have reduced the demand for Yangtze water, some distribution pipes to individual cities have yet to be constructed, and provinces are not using much diverted water because they face difficulties reconciling its relatively high price with the lower prices of local water. Nevertheless, both Chen et al. (2013) and Zhang et al. (2012) indicate that by 2030 it is planned to transfer $800-1000 \mathrm{~m}^{3} \mathrm{~s}^{-1}$ by this route $(25.2-$ $31.5 \mathrm{~m}^{3} \mathrm{yr}^{-1}$ )

We assume as follows. By 2030 the eastern route will be transferring $900 \mathrm{~m}^{3} \mathrm{~s}^{-1}$. This is a reduction in discharge that occurs below the Datong gauging station.

It is planned that the middle route will divert 12

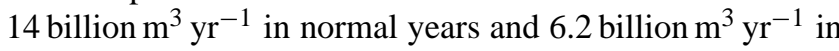
dry years (see http://www.nsbd.gov.cn). The water is sourced from the Danjiangkou Reservoir, located on the Han River, a tributary of the Yangtze. We assume that these conditions will hold in 2030. These imply reductions in discharge at Datong of $410 \mathrm{~m}^{3} \mathrm{~s}^{-1}$ under normal rules and $200 \mathrm{~m}^{3} \mathrm{~s}^{-1}$ under conservative rules. 


\section{A3 Other diversions}

In addition to the SNWDP, water is also diverted from the lower Yangtze (below Datong) to cities and agricultural areas. The history, current status and some projections of these diversions are comprehensively described by Chen et al. (2001) and Zhang et al. (2003, 2012). Zhang et al. (2003) provide historical data about the capacity of water extractions from 1958 to 2000 and also indicate net water extractions for November, January and March in the 1980s and by 2030. Chen et al. (2001) provide a summary of the findings of Zhang et al. (2003). Zhang et al. (2012) update the information provided by Zhang et al. (2003); in addition, they provide estimates of daily net abstractions for the dry seasons of 4 years.

These data indicate that the capacity to extract water from the Yangtze downstream of Datong has increased rapidly since the 1950s. However, the available data do not indicate that the net quantity of water abstracted from the Yangtze has increased over time, controlling for discharge, tides and local precipitation. Regression estimates of net abstractions (according to Zhang et al., 2012, their Fig. 4a) indicate that, net of tidal conditions, these depend on the sequence of the observation within the river year (tending to decrease and then rise), on the discharge (tending to rise with discharge) and on the year (tending to decrease slightly over time). These data imply that the estimates of discharge at Datong are biased estimates of discharges at the estuary and also that there is no evidence that this bias has changed over time.
However, Chen et al. (2013) indicate that new abstractions are planned. These imply an additional net reduction in discharge of $670 \mathrm{~m}^{3} \mathrm{~s}^{-1}$. (They consider this a low estimate of the new abstractions.) Zhang et al. (2003; Table 1) estimate that the net water abstractions from the Yangtze River will increase by about $830-940 \mathrm{~m}^{3} \mathrm{~s}^{-1}$ over current levels of abstraction, after including the effects of the eastern route of the SNWDP. The estimates of Zhang et al. (360-470 $\mathrm{m}^{3} \mathrm{~s}^{-1}$ net of the eastern route transfer) are low, but they do note that an additional $210 \mathrm{~m}^{3} \mathrm{~s}^{-1}$ of extractions are planned. We assume approximately this pair of estimates, $650 \mathrm{~m}^{3} \mathrm{~s}^{-1}$, but supplement this with a conservative rate of abstraction of $550 \mathrm{~m}^{3} \mathrm{~s}^{-1}$.

\section{A4 Summary}

There are three modifications to the discharge of the Yangtze River at its estuary, estimated under two conditions - conservative rules and normal rules. The discharge at Datong is modified by the operation of the Three Gorges hydropower station (except during the years after 2010-2011, when it was actually in operation) and by the operation of the middle route of the SNWDP); both have normal year and conservative rules of operation. Below Datong, additional water is extracted by the eastern route of the SNWDP and by more local abstractions (the latter of which also have normal and conservative rules of modification). The resulting implications for discharge at the estuary are illustrated in Fig. 8 of the paper. 


\section{Data availability}

A spreadsheet (.xlsx), containing the observations on discharge and salinity, the discharge data and the assumed abstractions, is available upon request to the corresponding author.

Author contributions. M. Webber performed the calculations and wrote the paper; M. T. Li, J. Chen, B. Finlayson, D. Chen and Z. Y. Chen provided the data; all authors contributed to the design of the research and commented on the results and conclusions.

Acknowledgements. The authors gratefully acknowledge ARC research grant DP110103381, which supported the research reported in this paper. They are grateful to Klaus Fraedrich (University of Hamburg), Ma Ji and Xiong Xianzhe (University of Melbourne), who kindly supplied some of the data, and to two referees for their comments.

Edited by: P. Regnier

\section{References}

An, Q., Wu, Y. Q., Taylor, S., and Zhao, B.: Influence of the Three Gorges Project on saltwater intrusion in the Yangtze River estuary, Environ. Geol., 56, 1679-1686, 2009.

Cai, F., Su, X. Z., Liu, J. H., Li, B., and Lei, G.: Coastal erosion in China under the condition of global climate change and measures for its prevention, Prog. Nat. Sci., 19, 415-426, 2009.

Chen, D., Webber, M., Finlayson, B., Barnett, J., Chen, Z. Y., and Wang, M.: Impact of water transfers from the lower Yangtze River on water security in Shanghai, Appl. Geogr., 45, 303-310, 2013.

Chen, X., Zong, Y., Zhang, E., Xu, J., and Li, S.: Human impacts on the Changjiang (Yangtze) River basin, China, with special reference to the impacts on the dry season water discharges into the sea, Geomorphology, 41, 111-123, 2001.

CNTV: Record intrusion of seawater affects 2 million residents of Shanghai, available at: http://english.cntv.cn/program/ newsupdate/20140224/102934.shtml (last access: 28 October 2015), 2014.

Dai, Z. J., Chu, A., Stive, M., Zhang, X. L., and Yan, H.: Unusual salinity conditions in the Yangtze esuary in 2006: impacts of an extreme drought or of the Three Gorges Dam?, Ambio, 40, 496505, 2011.

Finlayson, B. L., Barnett, J., Wei, T. Y., Webber, M., Li, M. T., Wang, M. Y., Chen, J., Xu, H., and Chen, Z. Y.: The drivers of risk to water security in Shanghai, Reg. Environ. Change, 13, 329-340, 2013.

Garson, G. D.: Generalized Linear Models/Generalized Estimating Equations, Statistical Publishing Associates, Asheboro, NC, USA, 2013.

Gong, W. P., Shen, J., and Jia, L. W.: Salt intrusion during the dry season in the Huangmaohai Estuary, Pearl River Delta, J. Marine Syst., 111-112, 235-252, 2013.
Gu, Y. and Yue, Q.: Analysis and prediction of saltwater intrusion in Chenhang water source region in Yangtze River estuary, Public Utilities, 18, 19-20, 2004.

Guo, S. L., Chen, J. H., Li, Y., Liu, P., and Li, T. Y.: Joint operation of the multi-reservoir system of the Three Gorges and the Qingjiang cascade reservoirs, Energies, 4, 1036-1050 2011.

Jiang, T., Kundzewicz, Z. W., and Su, B. D.: Changes in monthly precipitation and flood hazard in the Yangtze River basin, China Int. J. Climatol., 28, 1471-1481, 2008.

Kuang, C. P., Sun, B., and Liu, S. G.: Approach of moving boundary and its application in 3D tidal current simulation of Changjiang River estuary based on ECOMSED model, Acta Oceanol. Sin., 28, 78-85, 2009.

Li, C. A., Yin, H. F., and Yu, L. Z.: Silt transform characteristics and latent effect on fluvial system environment in Yangtze River, Resources and Environment in the Yangtze Basin , 9, 504-509, 2000 (in Chinese with English abstract).

Li, L., Zhu, J. R., and Wu, H.: Impacts of wind stress on saltwater intrusion in the Yangtze estuary, Science China - Earth Sciences , 55, 1178-1192, 2012.

Li, M. T., Chen, Z. Y., Finlayson, B., Wei, T., Chen, J., Wu, X., $\mathrm{Xu}, \mathrm{H}$., Webber, M., Barnett, J., and Wang, M.: Water diversion and sea-level rise: potential threats to freshwater supplies in the Changjiang River estuary, Estuar. Coast. Shelf S., 156, 52-60, 2014.

Liu, S., Zhong, G., Kuang, C., Sun, B, Gou, H., and Huang, W.: Effects of South-to-North Water Transfer Project on salinity intrusion in Yangtze estuary, Coastal Hazards , 2013, 119-128, doi:10.1061/9780784412664.012, 2013.

Savenije, H. H. G.: A one-dimensional model for salinity intrusion in alluvial estuaries, J. Hydrol., 85, 87-109, 1986.

Savenije, H. H. G.: Predictive model for salt intrusion in estuaries, J. Hydrol., 148, 203-218, 1993.

Shen, H. T., Mao, Z. C., and Zhu, J. R.: Saltwater Intrusion in the Changjiang Estuary, China Ocean Press, Beijing, 2003 (in Chinese with English summary).

Tao, H., Gemmer, M., Jiang, J. H., Lai, X. J., and Zhang, Z. X.: Assessment of CMIP3 climate models and projected changesof precipitation and temperature in the Yangtze River basin, China, Clim. Change, 111, 737-751, 2012.

Tong, C. F., Zheng, J. H., Zhang, C., and Guilbaud, C.: Salinity response to the runoff from Yangtze River basin at Qingcaosha reservoir area in Yangtze estuary, ASME 2010 29th International Conference on Ocean, Offshore and Arctic Engineering, Shanghai, China, 6-11 June 2010, 4, 247-255, 2010.

Wang, Y. G., Huang, H. M., and Li, X.: Critical discharge at Datong for controlling operation of South-to-North Water Transfer Project in dry seasons, Water Science and Engineering, 1, 47-58, 2008.

Xue, P. C., Chen, P., Ding, R. C., Beardsley, H., Lin, H., Ge, J., and Kong, Y.: Saltwater intrusion into the Changjiang River: a modelguided mechanism study, J. Geophys. Res., 114, C02006, doi:10.1029/2008JC004831, 2009.

Yang, G.: Impacts of the construction of key water conservancy projects in the Yangtze River and sea level rise on water quality of Shanghai water intake, Acta Geographica Sinica , 21, 123129, 2001. 
Zhang, E. F., Chen, X. Q., and Wang, X. L.: Water discharge changes of the Changjiang river downstream Datong during dry season, J. Geogr. Sci., 13, 355-362, 2003.

Zhang, E. F., Savenije, H. H. G., Wu, H., Kong, Y. Z., and Zhu, J. R.: Analytical solution for salt intrusion in the Yangtze Estuary, China, Estuar. Coast. Shelf S., 91, 492-501, 2011.

Zhang, E. F., Savenije, H. H. G., Chen, S. L., and Chen, J. Y.: Water abstraction along the lower Yangtze River, China, and its impact on water discharge into the estuary, Phys. Chem. Earth, 47-48, 76-85, 2012.
Zhao, R., Yang, Z., Sun, T., Chen, B., and Chen, G.: Freshwater inflow requirements for the protection of the critical habitat and the drinking water sources in the Yangtze River Estuary, China, Commun. Nonlinear Sci., 14, 2507-2518, 2009. 